\title{
molecules
}

ISSN 1420-3049

http://www.mdpi.org

Full Paper

\section{Highly Volatile Constituents of Vetiveria zizanioides Roots Grown under Different Cultivation Conditions}

\section{Patcharee Pripdeevech ${ }^{1}$, Sugunya Wongpornchai ${ }^{1, *}$ and Ampan Promsiri ${ }^{2}$}

${ }^{1}$ Department of Chemistry, Faculty of Science, Chiang Mai University, Chiang Mai, 50200, Thailand

2 Department of Soil Science and Conservation, Faculty of Agriculture, Chiang Mai University, Chiang Mai, 50200, Thailand

* Author to whom correspondence should be addressed; E-mail: scismhth@chiangmai.ac.th. Phone: (+66)-53-943341-5, ext. 120; Fax: (+66)-53-892277

Received: 29 August 2006; in revised form: 12 October 2006 / Accepted: 16 October 2006 / Published: 25 October 2006

\begin{abstract}
Roots of Vetiveria zizanioides Nash (Mae Hae; Thai ecotype) planted in three different cultivation systems (normal soil, normal soil with added microbes and semihydroponically) were extracted using a simultaneous steam distillation and solvent extraction (SDE) apparatus. Yields of the essential oils obtained were 0.27, 0.18 and $0.06 \%$, respectively. The separation profiles obtained by comprehensive two-dimensional gas chromatography (GC $\times \mathrm{GC}$ ) and solid phase microextraction (SPME)-GC $\times \mathrm{GC}$ analyses of the crude essential oils showed a total of 156 and 48 well-resolved components, respectively. The highly volatile fractions isolated from the three essential oils by SPME were subjected to analysis by GC-MS and 42 compounds were identified in total. Volatile component profiles of the oils obtained by normal soil and semi-hydroponic cultivation were similar, whereas a quantitative difference was noted in some major volatiles when the cultivation system containing microbes was utilized.
\end{abstract}

Keywords: Vetiveria zizanioides Nash, vetiver, semi-hydroponic cultivation, GC $\times$ GC, SPME-GC-MS 


\section{Introduction}

Vetiver, a plant of the Gramiceae family, is well known as an eco-friendly tool to prevent soil erosion [1,2]. Vetiver grass is also cultivated for the production of a commercially important essential oil used in perfumery and aromatherapy [3-5]. The essential oil is extracted from the roots of the vetiver grass, mainly from Vetiveria zizanioides. The complex odor profile of vetiver oil is dominated by a woody balsamic tonality of a very special kind. This tonality indicates the presence of some volatile compounds that have been reported to be mainly sesquiterpenes and their derivatives. Among these, the major active constituents identified are khusimol, vetivone, eudesmol, khusimone, zizaene, and prezizaene, which are considered to be the fingerprint of the oil [6-11].

Cultivation of vetiver grass is generally done using seedlings [12,13]. Recently, meristem tissue culture has been an alternative method for propagation of the grass, being bacteria- and fungus-free [9]. This method is usually followed by semi-hydroponic cultivation where the plants are transplanted into plastic baskets containing organic compost and their roots are allowed to grow downwards [14]. The advantages of a semi-hydroponic system for cultivation of vetiver grass are not only the more effective use of land, but also the increase in root aeration and real-time control of nutrient uptake, which all contribute to higher production yields and ease of harvesting. Obviously, the quality of the essential oil obtained from vetiver roots grown in a semi-hydroponic system is the most important factor to be considered, but to our knowledge there have been no reports concerning this.

In this research, the techniques of GC $\times$ GC, SPME-GC $\times$ GC, and SPME-GC-MS were applied to the analyses of the crude and the highly volatile fraction of essential oils obtained from the root of Thai vetiver grown in three different cultivation systems. These three systems are cultivation in normal soil, cultivation in normal soil with added microbes, and semi-hydroponic cultivation. The ability of these techniques to differentiate the quality of each essential oil in terms of its volatile composition derived from diverse soil conditions is demonstrated. Moreover, a quantitative comparison of highly volatiles and the key odorants of the vetiver essential oils obtained from the three cultivation systems is reported and discussed.

\section{Results and Discussion}

The vetiver root samples were extracted using a modified Likens-Nickerson apparatus. The resulting essential oils appeared as brown-yellow viscous liquids, obtained in 0.18, 0.27, and 0.06\% yields from vetiver cultivated in normal soil, normal soil with added microbes, and semihydroponically, respectively. The higher yield obtained by cultivation in normal soil with added microbes revealed the activity of the intracellular bacteria that were involved with the essential oil cells in the glands of vetiver roots, as reported in a previous study [9]. These microbes could conceivably be biotransforming the essential oil precursors, resulting in the increased yield. In contrast, vetiver oil from semi-hydroponic cultivation, which contained no fertilizer and no effective microbes, gave the lowest yield. The loss of volatile oil from the vetiver roots obtained from this cultivation system was quite high and was possibly due to the continual evaporation of volatiles as the roots were exposed to the atmosphere during the growing stage. Sensory evaluation results indicated the same burnt and 
woody aroma description, which meant that the cultivation methods appear to have no effect on the overall aroma characteristics of the oils.

GC $\times G C$ and SPME-GC $\times G C$ analysis

The GC $\times$ GC technique was used for analysis of the overall volatile constituents in the vetiver root essential oils obtained from three different cultivation systems, whereas the SPME-GC $\times$ GC technique was utilized to investigate the highly volatile fractions of the oils. The two systems employed a DB-5 x BP-20 column set. The comprehensive GC $\times$ GC contour plots shown in Figures $1 \mathrm{~A}$ and $1 \mathrm{~B}$ show the volatile constituents in the crude essential oil and in its highly volatile fraction obtained by GC $\times \mathrm{GC}$ and SPME-GC $\times$ GC, respectively. The peaks appearing in these GC $\times$ GC and SPME-GC $\times$ GC profiles of all the vetiver oils revealed in total 156 and 48 well-resolved volatile components, respectively. The GC $\times$ GC profiles showed a higher proportion of high molecular weight sesquiterpenes, while those of the SPME-GC $\times$ GC were richer in light sesquiterpenes. The results in this experiment indicated that identification of the crude essential oil components by GC-MS would be difficult and inaccurate due to the co-elution of many volatiles with the same GC retention times, whereas a few overlapped peaks were found in the profile of highly volatile fraction extracted by SPME.

Figure 1. The contour plots of volatile component profiles of vetiver essential oils obtained from normal soil cultivation using (A) GC×GC and (B) SPME-GC×GC.

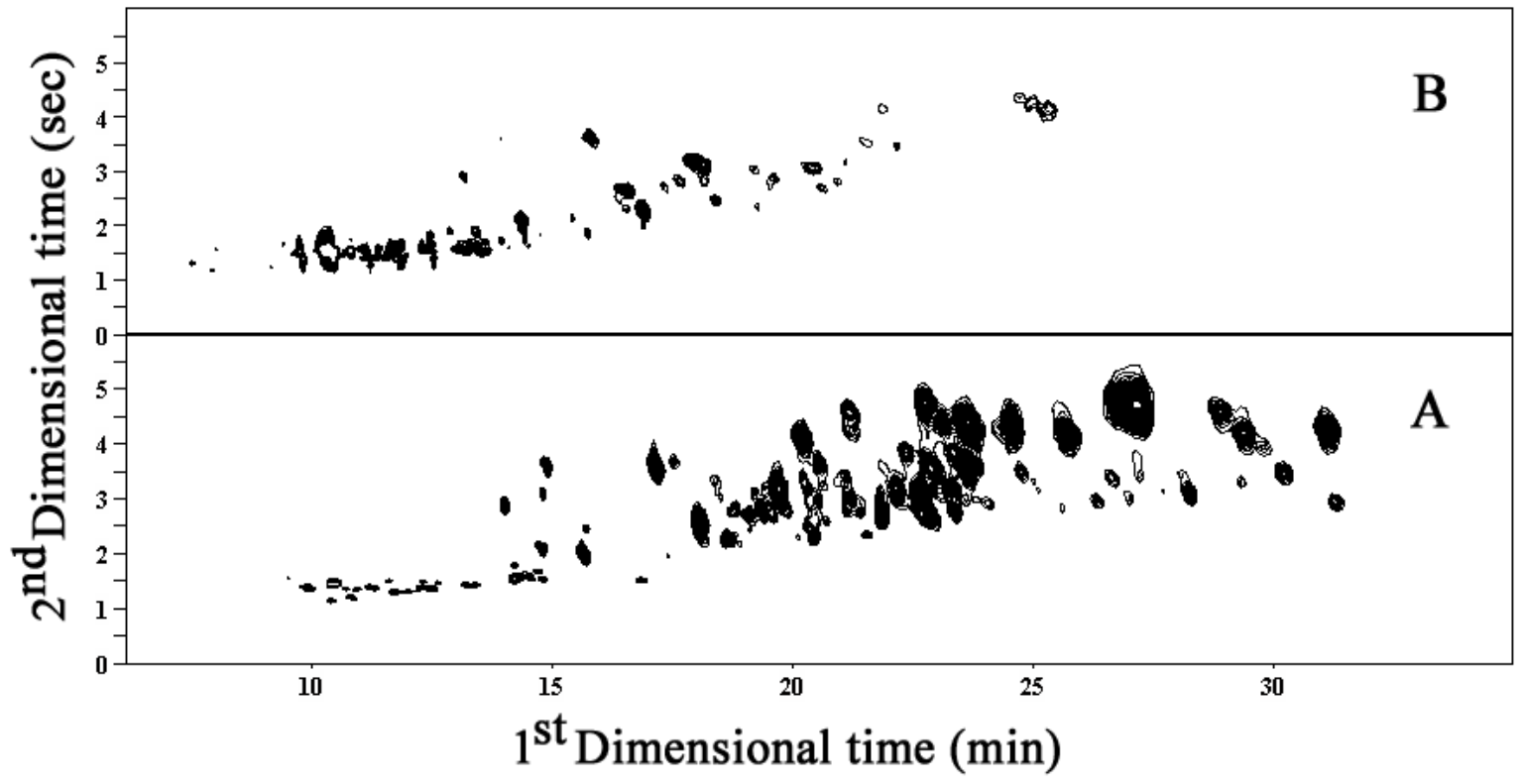

SPME-GC-MS Analysis

All SPME-GC-MS chromatograms and the identified volatile components, as well as their relative peak area percent values, are shown in Figure 2 and Table 1, respectively. Apart from the mass spectral comparison with the mass spectral library software, the volatile components were identified by comparing their Kovát indices with reported data [6-11]. 
Thirty-seven volatiles were identified in the oil obtained by vetiver cultivated in normal soil. Among these components, (Z)-9,10-dehydro-2-norzizaene (20.78\%), khusimone (20.57\%) and khusimol (11.11\%) were the major ones. For the oil obtained from vetiver cultivated in normal soil with added microbes, 39 volatile components were observed, with only (Z)-9,10-dehydro-2-norzizaene (46.03\%) being predominant. In addition, sesquicineole and delta-cadinene were detected only in the oil derived from cultivation in normal soil with added microbes, which probably resulted from an unidentified biotic factor [9]. Although both these compounds have been previously reported in vetiver oil derived from cultivation in normal soil [6], in our study these two components were not present in the SPME-GC-MS profile of the oil from root cultivated in normal soil, or they were present at concentrations below the detection limits. Three volatile components: $(+)(6 S, 10 R)-6,10$-dimethylbicyclo[4.4.0]dec-1-en-3-one, cadina-1(10),6,8-triene, and 9,10-dehydroisolongifolene are identified for the first time in essential oil of vetiver root in this report. The compound $(+)(6 S, 10 R)-6,10$ dimethylbicyclo[4.4.0]dec-1-en-3-one is an isomer of 2(3H)-naphthalenone constituents and it has been found to contribute to the distinctive flavor of grapefruit and citrus paradise [15]. Cadina1(10),6,8-triene and 9,10-dehydroisolongifolene occur in varieties of pummelos and citrus species [16] as well as in the essential oil of Sequoiadendron giganteum (Lindl.) Buchh. cultivated in Croatia [17].

Figure 2. SPME-GC-MS chromatograms of vetiver essential oils obtained from root cultivated in three different systems. A. normal soil B. normal soil with added microbes C. semi-hydroponic system.

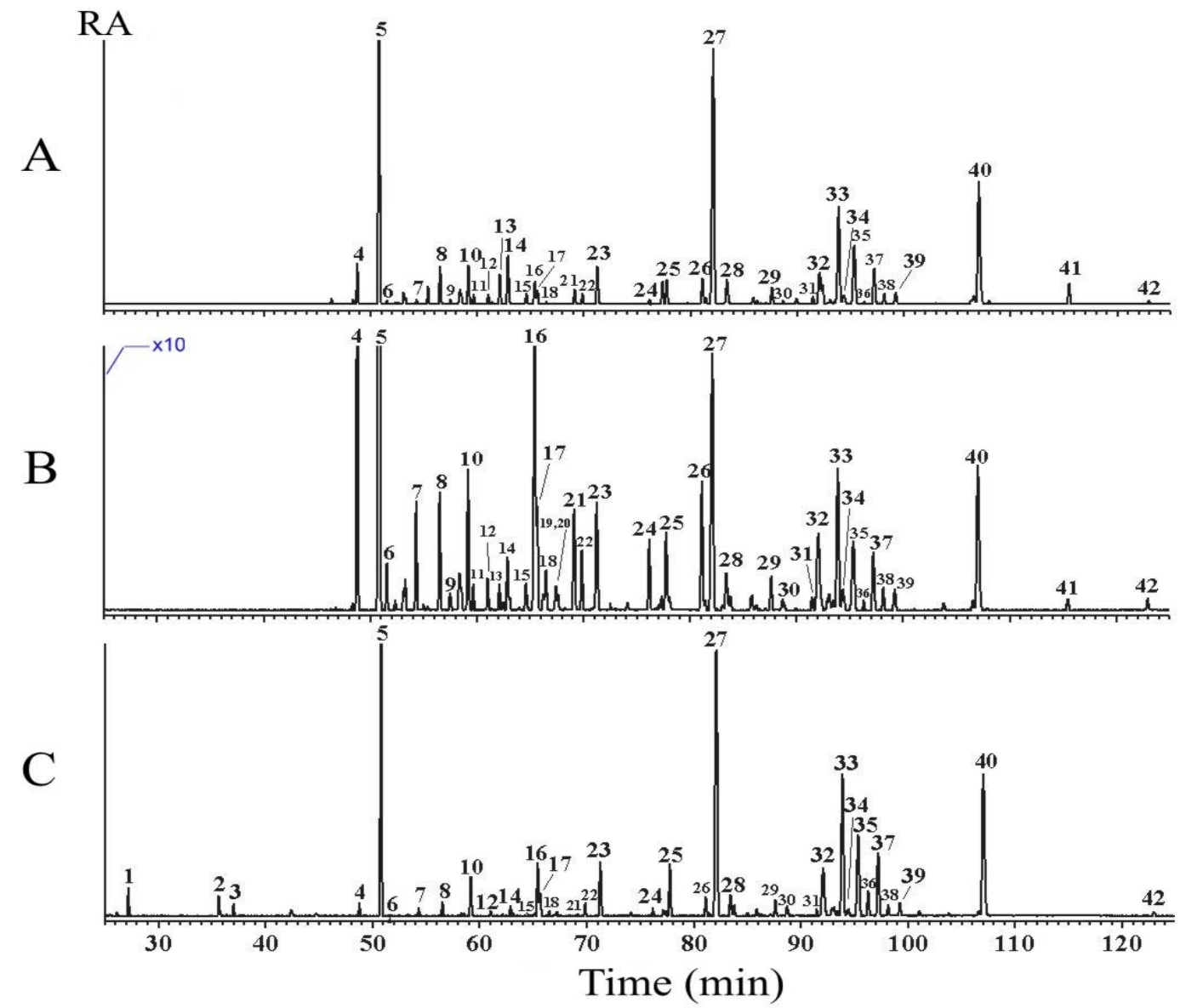


Table 1. Structural assignment and relative peak area percent of the volatile components in essential oils obtained from root of vertiver grass cultivated in three different systems.

\begin{tabular}{|c|c|c|c|c|c|c|c|}
\hline \multirow[b]{2}{*}{ No. ${ }^{a}$} & \multirow[b]{2}{*}{ Structural Assignment } & \multirow[b]{2}{*}{$K I^{c}$} & \multirow[b]{2}{*}{$\begin{array}{c}\text { Adams' } \\
\text { RI }\end{array}$} & \multirow[b]{2}{*}{ Reference $^{d}$} & \multicolumn{3}{|c|}{ Relative Peak Area (\%) $\pm \mathrm{SD}^{e}$} \\
\hline & & & & & $\begin{array}{c}\text { Normal } \\
\text { soil }\end{array}$ & $\begin{array}{l}\text { Normal } \\
\text { soil with } \\
\text { microbes }\end{array}$ & $\begin{array}{l}\text { Semi- } \\
\text { hydroponic }\end{array}$ \\
\hline 1 & 1-nonanal ${ }^{1,3}$ & 1294 & & 18 & & & $1.06 \pm 0.01$ \\
\hline 2 & nonanoic acid ${ }^{1,3}$ & 1345 & & 19 & & & $0.99 \pm 0.01$ \\
\hline 3 & 1-decanal ${ }^{1,3}$ & 1352 & & 20 & & & $0.45 \pm 0.02$ \\
\hline 4 & (E)-9,10-dehydro-2-norzizaene ${ }^{1}$ & 1393 & & 21 & $1.87 \pm 0.06$ & $5.30 \pm 0.01$ & $0.46 \pm 0.01$ \\
\hline 5 & (Z)-9,10-dehydro-2-norzizaene ${ }^{1}$ & 1405 & & 21 & $20.78 \pm 0.05$ & $46.03 \pm 0.02$ & $14.71 \pm 0.02$ \\
\hline 6 & alpha-funebrene $e^{1,2,3}$ & 1406 & 1403 & 6 & $0.14 \pm 0.02$ & $0.60 \pm 0.02$ & $0.02 \pm 0.01$ \\
\hline 7 & 2-norzizaene ${ }^{1}$ & 1417 & & 11 & $0.20 \pm 0.02$ & $1.56 \pm 0.03$ & $0.29 \pm 0.01$ \\
\hline 8 & acora-2,4-diene $^{1}$ & 1425 & & 6 & $1.93 \pm 0.02$ & $1.73 \pm 0.02$ & $0.65 \pm 0.01$ \\
\hline 9 & alpha-cedrene $e^{1,2}$ & 1430 & 1412 & 6 & $0.19 \pm 0.01$ & $0.28 \pm 0.02$ & \\
\hline 10 & cascarilladiene $^{1}$ & 1436 & & 6 & $2.16 \pm 0.04$ & $2.27 \pm 0.04$ & $2.04 \pm 0.01$ \\
\hline 11 & $\begin{array}{l}\text { 11,12,13-tri-nor-eremophil- } \\
\text { 1(10)-en-7-one }{ }^{1}\end{array}$ & 1442 & & 6 & $0.43 \pm 0.02$ & $0.34 \pm 0.02$ & \\
\hline 12 & gamma-elemene $e^{1,2}$ & 1451 & 1437 & 6 & $0.48 \pm 0.02$ & $0.47 \pm 0.02$ & $0.18 \pm 0.01$ \\
\hline 13 & prezizaene $^{1,2}$ & 1459 & 1450 & 6 & $1.55 \pm 0.03$ & $0.35 \pm 0.01$ & \\
\hline 14 & khusimene $^{1,2}$ & 1462 & 1455 & 6 & $3.04 \pm 0.39$ & $0.89 \pm 0.02$ & $0.42 \pm 0.02$ \\
\hline 15 & ar-curcumene $e^{1,2}$ & 1468 & 1481 & 6 & $0.60 \pm 0.01$ & $0.44 \pm 0.01$ & $0.09 \pm 0.01$ \\
\hline 16 & 4,7-epoxy-spirovetiva-2,11-diene ${ }^{1}$ & 1471 & & 6 & $1.35 \pm 0.04$ & $5.59 \pm 0.02$ & $2.94 \pm 0.02$ \\
\hline 17 & alpha-amorphene $e^{1,2}$ & 1474 & 1485 & 6 & $0.76 \pm 0.01$ & $1.47 \pm 0.01$ & $1.30 \pm 0.01$ \\
\hline 18 & cis-eudesma-6,11-diene $\mathrm{e}^{1,2}$ & 1490 & 1490 & 6 & $0.07 \pm 0.02$ & $0.65 \pm 0.02$ & $0.14 \pm 0.01$ \\
\hline 19 & sesquicineole $^{1}$ & 1502 & & 6 & & $0.34 \pm 0.03$ & \\
\hline 20 & delta-cadinene $e^{1,2}$ & 1508 & 1523 & 6 & & $0.22 \pm 0.01$ & \\
\hline 21 & gamma-vetivenene $e^{1,2}$ & 1518 & 1533 & 6 & $0.83 \pm 0.13$ & $1.83 \pm 0.01$ & $0.07 \pm 0.01$ \\
\hline 22 & 10,11-epoxy-eremophil-1-ene ${ }^{1}$ & 1538 & & 6 & $0.56 \pm 0.02$ & $0.95 \pm 0.05$ & $0.55 \pm 0.02$ \\
\hline 23 & $\begin{array}{c}(+)(6 \mathrm{~S}, 10 \mathrm{R})-6,10-\text { dimethylbicyclo- } \\
{[4.4 .0] \mathrm{dec}-1 \text {-en-3-one }{ }^{1}}\end{array}$ & 1550 & & 15 & $2.44 \pm 0.02$ & $2.00 \pm 0.09$ & $3.21 \pm 0.01$ \\
\hline 24 & beta-calacorene ${ }^{1,2}$ & 1566 & 1546 & 6 & $0.22 \pm 0.01$ & $1.18 \pm 0.01$ & $0.30 \pm 0.01$ \\
\hline 25 & 15-nor-funebran-3-one ${ }^{1}$ & 1574 & & 6 & $1.45 \pm 0.02$ & $1.46 \pm 0.01$ & $2.91 \pm 0.01$ \\
\hline 26 & cis-eudesm-6-en-11-ol $^{1}$ & 1579 & & 6 & $1.58 \pm 0.04$ & $2.37 \pm 0.01$ & $1.09 \pm 0.03$ \\
\hline 27 & khusimone $^{1,2}$ & 1598 & 1604 & 6 & $20.57 \pm 0.01$ & $6.13 \pm 0.07$ & $20.91 \pm 0.01$ \\
\hline 28 & 13-nor-cis-eudesm-6-en-11-one ${ }^{1}$ & 1602 & & 6 & $1.80 \pm 0.02$ & $0.66 \pm 0.02$ & $1.35 \pm 0.01$ \\
\hline 29 & trans-dracunculifoliol $^{1}$ & 1612 & & 6 & $1.07 \pm 0.02$ & $0.63 \pm 0.02$ & $0.77 \pm 0.01$ \\
\hline 30 & 13-nor-eremophila-1(10)-en-11-one ${ }^{1}$ & 1618 & & 6 & $0.18 \pm 0.02$ & $0.21 \pm 0.02$ & $0.55 \pm 0.01$ \\
\hline 31 & eudesm-4(15),7-dien-3 $\beta$-ol $^{1}$ & 1638 & & 6 & $0.43 \pm 0.02$ & $0.22 \pm 0.02$ & $0.27 \pm 0.01$ \\
\hline 32 & beta-eudesmol $^{1,2}$ & 1644 & 1651 & 6 & $2.61 \pm 0.02$ & $2.37 \pm 0.02$ & $4.48 \pm 0.01$ \\
\hline 33 & $(E)$-opposita-4(15),7(11)-dien-12-al ${ }^{1}$ & 1651 & & 6 & $7.71 \pm 0.02$ & $3.00 \pm 0.06$ & $10.55 \pm 0.01$ \\
\hline 34 & prezizaan-15-al $^{1}$ & 1660 & & 6 & $0.67 \pm 0.01$ & $0.41 \pm 0.02$ & $0.51 \pm 0.03$ \\
\hline 35 & 2-epi-ziza-6(13)-en-3 $\alpha$-ol ${ }^{1}$ & 1665 & & 6 & $5.31 \pm 0.02$ & $1.83 \pm 0.03$ & $6.85 \pm 0.16$ \\
\hline 36 & zizanal $^{1,2}$ & 1671 & 1697 & 6 & $0.09 \pm 0.01$ & $0.12 \pm 0.01$ & $1.40 \pm 0.01$ \\
\hline 37 & khusian-2-ol ${ }^{1}$ & 1687 & & 6 & $2.74 \pm 0.02$ & $1.24 \pm 0.01$ & $4.65 \pm 0.01$ \\
\hline 38 & $(E)$-opposita-4(15),7(11)-dien-12-ol ${ }^{1}$ & 1690 & & 6 & $0.59 \pm 0.02$ & $0.41 \pm 0.02$ & $0.56 \pm 0.01$ \\
\hline
\end{tabular}


Table 1. Cont.

\begin{tabular}{|c|c|c|c|c|c|c|c|}
\hline 39 & cadina-1(10),6,8-triene $^{1}$ & 1694 & & 16 & $0.83 \pm 0.03$ & $0.43 \pm 0.02$ & $0.79 \pm 0.01$ \\
\hline 40 & khusimol $^{1,2}$ & 1762 & 1743 & 6 & $11.11 \pm 0.05$ & $3.55 \pm 0.04$ & $12.21 \pm 0.02$ \\
\hline 41 & 9,10-dehydro-isolongifolene ${ }^{1}$ & 1798 & & 17 & $1.43 \pm 0.01$ & $0.19 \pm 0.01$ & \\
\hline 42 & nootkatone ${ }^{1,2,3}$ & 1804 & 1807 & 6 & $0.21 \pm 0.02$ & $0.21 \pm 0.01$ & $0.31 \pm 0.01$ \\
\hline \multicolumn{5}{|c|}{ Total number of volatile compor } & 37 & 39 & 36 \\
\hline
\end{tabular}

${ }^{a}$ Compounds in Figure 2; ${ }^{b}$ Identification: 1, mass spectrum; 2, Kovát indices; 3, standard compound;

${ }^{c}$ Kovát indices on DB-5 column; ${ }^{d}$ Reference having same mass spectrum; ${ }^{e}$ Standard deviations of three analyses

Thirty six volatiles were detected in the oil from semi-hydroponically cultivated vetiver. Khusimone (20.91\%), (Z)-9,10-dehydro-2-norzizaene (14.71\%), khusimol (12.21\%), and (E)-opposita4(15),7(11)-dien-12-al (10.55\%) were present as the major odors. Compared to vetiver oils obtained from soil cultivation, the odor volatiles profile was similar to that obtained by cultivation in normal soil, but strikingly different from that obtained by cultivation in normal soil with added microbes. Additionally, two low molecular weight aldehydes, 1-nonanal and decanal, and the fatty acid nonanoic acid, were observed and present in trace amounts. These aldehydes have never been observed in the vetiver oil compositions reported in early studies. It was also suggested that these components have a limited effect on the aroma characteristic of the vetiver oil. On the other hand, six volatile components: alpha-cedrene, 11,12,13-tri-nor-eremophil-1(10)-en-7-one, prezizaene, sesquicineole, delta-cadinene and 9,10-dehydroisolongifolene were absent from the oil sample obtained using semi-hydroponic cultivation. Although the semi-hydroponic cultivation has several advantages, such as being simple to plant and requiring a smaller space and budget, this system yielded vetiver root with a much lower percentage of essential oil than that obtained by cultivation in normal soil with added microbes.

\section{Conclusions}

Methods of cultivation have significant effects on both percentage yield and volatiles composition of the vetiver root essential oils obtained by simultaneous steam distillation and solvent extraction. Among the three cultivation conditions, the system utilizing microbes gave the highest yield of essential oil along with higher contents of some low molecular weight volatiles such as 2-norzizaene and its derivatives and $\gamma$-vetivenene. The oil obtained by semi-hydroponic cultivation, despite its low percentage yield, gave the volatile component profile similar to that obtained by normal soil cultivation.

\section{Experimental}

\section{Plant Materials}

Mae Hae, a Vetiveria zizanioides Nash. ecotype from Northern Thailand was grown by three different cultivation systems. Bare root tillers of vetiver grass were employed as planting material for all systems. In the first and second systems, the plants were grown in a potting mixture of sandy soil, rice husks and cow dung at the ratio 2:2:1, respectively. Rock phosphate and feldspar were also added 
to the potting mixture for nutrient supplement at concentrations of $400 \mathrm{~g}$ and $2 \mathrm{~kg}$ per ton, respectively. No microbial inoculation was used in the first system. In the second system, the vetiver grass was inoculated with arbuscular mycorrhizal fungi, azospirillum, and azetobacter $\mathrm{N}_{2}$-fixing bacteria and potassium containing silicate mineral dissolving bacteria. Microbial inoculation was done at the time the planting materials were transplanted by placing each type of microbial inoculums below the base of planting materials at the following proportions: 100 infective propagule for arbuscular mycorrhizal fungi and $5 \times 10^{8}$ cells for each bacterium per plant. In the first month, the vetiver plants were grown in the nursery and small plastic bags containing $500 \mathrm{~g}$ of potting mixture per bag were used as container. After that, the plants were transferred to $2500 \mathrm{~mL}$ plastic tubes containing the same potting mixture for outdoor cultivation. In the third system, the plants from the first system were separated and taken out of the plastic bags while still in the nursery. Most of the potting mixtures were removed from the root systems and then the plants were transplanted into the mixture of rice husks and compost in plastic baskets. Some roots of the vetiver grass passed through a basket and extended into the lower part of the container in which they were fed with nutrients solution. After five months, the roots of vetiver grass from each system were taken out from the whole plants.

\section{Extraction of the Vetiver Oil}

The vetiver roots from each growing system were washed and dried at room temperature for 2 weeks. Then, the root samples were placed in an oven at $70{ }^{\circ} \mathrm{C}$ for $24 \mathrm{~h}$ before comminuting and extracting by Likens-Nickerson SDE apparatus for 5 h.. The extraction was carried out in a modified Likens-Nickerson SDE apparatus for $5 \mathrm{~h}$. Each blended vetiver root sample (50 g) and distilled water (200 mL) were added to a $500 \mathrm{~mL}$ round-bottom flask. Dichloromethane (150 mL) was added to another 250-mL round-bottom flask. Both flasks were connected to the apparatus, and more dichloromethane and distilled water were added into the central arm. The flask containing dichloromethane was heated by using a water bath at $50{ }^{\circ} \mathrm{C}$ and the flask containing vetiver root and distilled water was heated by using a paraffin oil bath at $200{ }^{\circ} \mathrm{C}$. After extraction, the distillate in a 250 $\mathrm{mL}$ flask was dried over anhydrous sodium sulfate $(3 \mathrm{~g})$ and concentrated using vacuum rotary evaporation and stored in headspace vials. Extraction of each vetiver root sample was performed in triplicate.

\section{$G C \times G C$}

GC $\times$ GC system was performed using a Hewlett-Packard HP 6890 (Agilent Technologies, USA) instrument equipped with a flame ionization detector (FID), fitted with a longitudinally modulated cryogenic system (LMCS Everest model, Chromatography Concepts, Doncaster, Australia) and operated at a $100 \mathrm{~Hz}$ data acquisition rate using the Chemstation software (Agilent Technologies, USA). A modulation frequency was operated at $6 \mathrm{~s}$ per cycle. The thermostatically controlled cryogenic trap was maintained at about $-20{ }^{\circ} \mathrm{C}$ for the duration of each analysis. The column set comprised a $30 \mathrm{~m}$ x $0.25 \mathrm{~mm}$ x $0.25 \mu \mathrm{m}$ film thickness DB-5 (Agilent Technologies, U.S.A.) coupled with a $1.0 \mathrm{~m}$ x $0.1 \mathrm{~mm}$ x $0.1 \mu \mathrm{m}$ film thickness BP-20 (SGE International, Ringwood, Australia). The column temperature was programmed from $120^{\circ} \mathrm{C}$ to $180{ }^{\circ} \mathrm{C}$ at a rate of $2{ }^{\circ} \mathrm{C} / \mathrm{min}$. The split (10:1) 
injection and detector temperature were operated at 250 and $260{ }^{\circ} \mathrm{C}$, respectively. Hydrogen gas was used as carrier gas with a flow rate of $1.5 \mathrm{~mL} / \mathrm{min}$. The GC was operated in constant flow mode.

\section{SPME-GC $\times G C$}

Essential oil $(10 \mu \mathrm{L})$ was placed in a $22 \mathrm{~mL}$ headspace bottle sealed with a PTFE/silicone septum (Restek Corp., Bellefonte, PA, USA) and an aluminium cap. The sample bottle was incubated in a water bath at $70^{\circ} \mathrm{C}$ for 15 min before being subjected to extraction by SPME. A $1 \mathrm{~cm}$ long SPME fiber (Supelco, Bellefonte, PA, USA) coated with a $100 \mu \mathrm{m}$ thick layer of polydimethylsiloxane (PDMS) was mounted in the manual SPME holder and preconditioned for $2 \mathrm{~h}$ in a GC injection port set at 250 ${ }^{\circ} \mathrm{C}$. By insertion through the septum of the sample bottle, the fiber was then exposed to the sample headspace for 20 min prior to desorption of the volatiles into the splitless injection port of the GC $\times \mathrm{GC}$ instrument in which all condition were the same as that used for GC×GC analysis.

\section{SPME-GC-MS}

The volatile constituents from SPME of vetiver essential oil were analyzed using an HP model 6890 gas chromatograph equipped with an HP-5MS (5\% phenyl-polymethylsiloxane) capillary column (60 m x 0.25 mm i.d., film thickness $1.00 \mu \mathrm{m}$; Agilent Technologies, USA) interfaced to an HP model 5973 mass-selective detector. The oven temperature was initially held at $110{ }^{\circ} \mathrm{C}$ for $1 \mathrm{~min}$ and then increased by $1{ }^{\circ} \mathrm{C} / \mathrm{min}$ to $150{ }^{\circ} \mathrm{C}$ with a hold time of $1 \mathrm{~min}$. Then the temperature was increased at a rate of $0.5{ }^{\circ} \mathrm{C} / \mathrm{min}$ to $200{ }^{\circ} \mathrm{C}$ with a final hold time of $1 \mathrm{~min}$. The injector and detector temperatures were 250 and $280^{\circ} \mathrm{C}$, respectively. Purified helium was used as the carrier gas at a flow rate $1 \mathrm{~mL} / \mathrm{min}$. EI mass spectra were collected at $70 \mathrm{eV}$ ionization voltages over the range of $\mathrm{m} / \mathrm{z} 29-300$. The electron multiplier voltage was $1150 \mathrm{~V}$. The ion source and quadrupole temperatures were set at $230{ }^{\circ} \mathrm{C}$ and $150{ }^{\circ} \mathrm{C}$, respectively. Identification of volatile components was performed by comparison of their Kovát retention indices, relative to $\mathrm{C}_{8}-\mathrm{C}_{22} \mathrm{n}$-alkanes, and comparison of the mass spectra of individual components with the reference mass spectra in the Wiley 275 and NIST 98 databases with corresponding data of components in vetiver oil [12-15].

\section{Acknowledgements}

Great appreciation is given to M.R. Samjamjars Rajani and the Royal Project for providing vetiver grass (Mae Hae ecotype) and to the Postgraduate Education and Research in Chemistry Program (PERCH) for the support of GC $\times$ GC instrument. Financial support from the Thailand Research Fund through the Royal Golden Jubilee Ph.D. Program (Grant No. PHD/0198/2546) to P. Pripdeevech and S. Wongpornchai is acknowledged.

\section{References}

1. Dalton, P.A.; Smith, R.J.; Truong, P.N.V. Vetiver grass hedges for erosion control on a cropped flood plain: hedge hydraulics. Agr. Water Manage. 1996, 31, 91-104. 
2. Tscherning, K.; Leihner, D.E.; Hilger, T.H.; Müller-Sämann, K.M.; El Sharkawy, M.A. Grass barriers in cassava hillside cultivation: Rooting patterns and root growth dynamics. Field Crop. Res. 1995, 43, 131-140.

3. Chowdhury, A.R.; Kumar, D.; Lohani, H. GC-MS analysis of essential oils of Vetiveria zizanioides (Linn.) Nash. roots. Fafai J. 2002, April-June, 33-35.

4. Weyerstahl, P.; Marschall, H.; Splittgerber, U.; Wolf, D. New sesquiterpene ethers from Vetiver oil. Liebigs Ann. 1996, 1195-1199.

5. Bowles, J. E.; Griffiths, D.M.; Quirk, L.; Brownrigg, A.; Croot, K. Effects of essential oils and touch on resistance to nursing care procedures and other dementia-related behaviours in a residential care facility. Int. J. Aromat. 2002, 12, 22-29.

6. Weyerstahl, P.; Marschall, H.; Splittgerber, U.; Wolf, D.; Surburg, H. Constituents of Haitian vetiver oil. Flavour Fragrance J. 2000, 15, 395-412.

7. Sellier, N.; Cazaussus, A. Structure determination of sesquiterpenes in Chinese vetiver oil by gas chromatography-tendem mass spectrometry. J. Chromatogr. 1991, 557, 454-458.

8. Martinez, J.; Rosa, P.T.V.; Menut, C.; Leydet, A.; Brat, P.; Pallet, D.; Meireles, M.A.A. Valorization of Brazilian vetiver (Vetiveria zizanioides (L.) Nash ex Small) Oil. J. Agr. Food Chem. 2004, 52, 6578-6584.

9. Adams, R.P.; Habte, M.; Park, S.; Dafforn, M.R. Preliminary comparison of vetiver root essential oils from cleansed (bacteria- and fungus-free) versus non-cleansed (normal) vetiver plants. Biochem. Syst. Ecol. 2004, 32, 1137-1144.

10. Hanayama, N.; Kido, F.; Tanaka, R.; Uda, H.; Yoshikoshi, A. The structures of zizanoic acid and related constituents. Tetrahedron 1973, 29, 945-954.

11. Weyerstahl, P.; Marschall, H.; Splittgerber, U.; Wolf, D. Analysis of the polar fraction of Haitian vetiver oil. Flavour Fragrance J. 2000, 15, 153-173.

12. Chen, Y.; Shen, Z.; Li, X. The use of vetiver grass (Vetiveria zizanioides) in the phytoremediation of soils contaminated with heavy metals. Appl. Geochem. 2004, 19, 1553-1565.

13. Chiu, K.K.; Ye, Z.H.; Wong, M.H. Growth of Vetiveria zizanioides and Phragmities australis on $\mathrm{Pb} / \mathrm{Zn}$ and $\mathrm{Cu}$ mine tailings amended with manure compost and sewage sludge: A greenhouse study. Bioresour. Technol. 2006, 97, 158-170.

14. Marcacci, S.; Raveton, M.; Ravanel, P.; Schwitzguébel, J.P. Conjugation of atrazine in vetiver (Chrysopogon zizanioides Nash) grown in hydroponics. Environ. Exp. Bot. 2006, 56, 205-215.

15. MacCleod, W.D. Constitution of nootkatone, nootkatene, and valencene. Tetrahedron Lett. 1965, 52, 4779-4783.

16. Sawamura, M.; Shichiri, K.; Ootani, Y.; Zheng, X.H. Volatile constituents of several varieties of pummelos and characteristics among citrus species. Agric. Biol. Chem. 1991, 55, 2571-2578.

17. Jerkovic, I.; Mastelic, J.; Milos, M. Chemical composition of the essential oil of Sequoiadendron giganteum (Lindl.) Buchh. cultivated in Croatia. J. Essent. Oil Res. 2003, 15, 36-38.

18. Maccoll, A.; Mruzek, M.N. Low-energy, low-temperature mass spectra.V. 5-Alkanals. Org. Mass Spectrom. 1986, 21, 251-258.

19. Maccoll, A. Low-energy, low-temperature mass spectra. Part 11. The spectra of the alkanoic acids. Int. J. Mass Spectrom. Ion Process 1988, 86, 227-234. 
20. Ferreira, V.; Cullere, L.; Lopez, R.; Cacho, J. Determination of important odor-active aldehydes of wine through gas chromatography-mass spectrometry of their O-(2,3,4,5,6-pentafluorobenzyl) oximes formed directly in the solid phase extraction cartridge used for selective isolation. $J$. Chromatogr. A 2004, 1028, 339-345.

21. Hoffmann, H.M.R.; Henning, R. Synthesis of 2-norzizaene and 9,10-dehydro-2-norzizaene (7,7dimethyl-6-methylidenetricyclo[6.2.1.01,5]undec-9-ene) via intramolecular allyl cation induced cycloaddition. Helv. Chim. Acta 1983, 66, 828-841.

Sample availability: Standard compounds listed in Table 1 are available from the authors.

(C) 2006 by MDPI (http://www.mdpi.org). Reproduction is permitted for noncommercial purposes. 